\title{
PENGARUH PROMOSI PENJUALAN “PURCHASE WITH PURCHASE” TERHADAP MOTIVASI BELANJA DAN KEPUTUSAN PEMBELIAN
}

\author{
Sadana Devica \\ Program Studi Manajemen Pemasaran Politeknik Ubaya \\ Jalan Ngagel Jaya Selatan 169, Surabaya \\ sadana.devica@staff.ubaya.ac.id
}

\begin{abstract}
The aim of this study is to analyze the effect of "purchase with purchase" promotion on shopping motivation and consumer purchasing decisions. This research was conducted on 150 respondents by answering the questions posed in the questionnaire which was divided into three case simulations. Analysis of data processing in this study uses a regression method which includes correlation analysis, $t$ test and $F$ test. The results of processing respondents' answers indicate that "purchase with purchase" promotion has a significant and positive effect on hedonic purchase motivation, utilitarian purchase motivation, and consumer purchasing decisions. In addition, the results of this study indicate that "purchase with purchase" promotions have a greater influence on utilitarian purchase motivation.
\end{abstract}

Keywords: promotion, hedonic, utilitarian, purchasing decision.

\begin{abstract}
ABSTRAK
Tujuan dari penelitian ini adalah untuk menganalisis pengaruh promosi dalam bentuk "purchase with purchase" terhadap motivasi belanja dan keputusan pembelian konsumen. Penelitian ini dilakukan terhadap 150 orang responden dengan cara menjawab pertanyaan yang diajukan di dalam kuesioner yang terbagi dalam tiga simulasi kasus. Analisis pengolahan data pada penelitian ini menggunakan metode regresi yang meliputi analisis korelasi, uji t, dan uji F. Hasil dari pengolahan jawaban responden menunjukkan bahwa promosi dalam bentuk "purchase with purchase" berpengaruh signifikan dan positif terhadap motivasi pembelian hedonik, motivasi pembelian utilitarian, serta keputusan pembelian konsumen. Selain itu, hasil dari penelitian ini menunjukkan bahwa promosi dalam bentuk "purchase with purchase" berpengaruh lebih besar terhadap motivasi pembelian utilitarian.
\end{abstract}

Kata kunci: promosi, hedonik, utilitarian, keputusan pembelian. 


\section{PENDAHULUAN}

Perkembangan bisnis ritel di Indonesia sangatlah pesat, terutama keberadaannya di kota-kota besar. Salah satu contohnya adalah keberadaan ritel modern seperti Superindo, Indomaret, Guardian, dan Watson yang berdiri di lokasi-lokasi strategis atau di dalam pusat perbelanjaan sebagai salah satu cara untuk menguasai pangsa pasar di wilayah tertentu. Persaingan bisnis antar sesama pengelola ritel tentunya dilakukan tidak hanya dengan menawarkan lokasi dan fasilitas, tetapi juga melalui penawaran promosi harga. Promosi harga adalah cara bagi penjual untuk membedakan konsumen berdasarkan tingkat harga (Monroe, 2003).

Namun, perbedaan harga untuk suatu produk atau layanan yang sama dapat menimbulkan persepsi ketidakwajaran dari konsumen (Feinberg et al., 2002; Xia et al., 2004). Xia et al. (2010) juga menjelaskan bahwa beberapa riset telah dilakukan dengan menggunakan taktik promosi harga yang berbeda-beda. Hasil riset menunjukkan bahwa tingkat usaha yang dirasakan konsumen untuk mendapatkan potongan harga berpengaruh secara negatif terhadap persepsi kewajaran ketika konsumen menolak untuk membeli barang dengan harga promosi. Kivets and Zheng (2017) mengungkapkan bahwa riset mengenai dampak variabel bauran pemasaran terhadap keputusan pembelian konsumen pada produk hedonik dan produk utilitarian masih sangat terbatas. Perusahaan sering menggunakan promosi pemasaran, namun tidak diketahui apa dan mengapa konsumen merespon promosipromosi tersebut secara berbeda, yaitu apakah konsumen melakukan pembelian secara hedonik atau pembelian secara utilitarian. Liu and Chou (2015) mengungkapkan bahwa promosi penjualan sering ditampilkan dalam bentuk budling products. Misalnya, toko serba ada di Taiwan sering menawarkan promosi seperti "beli sandwich dan minuman hanya seharga NT \$X." Kamins et al. (2009) dan Raghubir (2004) juga menjelaskan bahwa pelanggan McDonald's lebih menyukai paket value meals, yang terdiri dari hamburger, kentang goreng, dan minuman dengan harga yang lebih pasti. Promosi umum lainnya juga menampilkan hadiah gratis, seperti mainan gratis yang ditawarkan oleh McDonald's apabila konsumen membeli paket happy meal. Dalam beberapa kasus, promosi dengan memberikan hadiah gratis merupakan versi alternatif dari promosi budling products. Misalnya, "beli shampo dan kondisioner seharga $\$ X^{\prime \prime}$ secara ekonomi setara dengan "beli shampo seharga \$X dan konsumen akan mendapatkan kondisioner gratis." Menurut Smith and Sinha (2000) menyatakan bahwa konsumen cenderung untuk lebih memilih program "beli satu, gratis satu" (free gift promotions) dibandingkan dengan "beli dua, dapatkan diskon 50\%” (price bundle).

Beberapa ritel di Indonesia pada dasarnya juga saling berkompetisi dengan melakukan aktivitas promosi penjualan yang serupa seperti yang telah dipaparkan sebelumnya. Namun, adanya kemungkinan konsumen mulai tidak loyal untuk berbelanja di satu tempat saja mulai disadari oleh pengelola bisnis ritel. Hal tersebut terjadi karena konsumen hanya akan berbelanja pada saat terdapat promosi penjualan yang menarik. Setelah program promosi tersebut berakhir, konsumen akan berpikir ulang untuk berbelanja di tempat yang sama dan mencari ritel 
lain dengan program promosi penjualan yang lebih menarik dan menguntungkan bagi mereka. Oleh karena itu, program promosi penjualan harus dikembangkan lebih kreatif agar konsumen menjadi tertarik untuk melakukan pembelian ulang di ritel yang sama dan mampu membedakan manakah program promosi penjualan yang paling menguntungkan bagi mereka. Salah satu contohnya adalah program promosi penjualan "purchase with purchase" yang dewasa ini sering dijumpai di berbagai jaringan drug store, seperti: Guardian, Superindo, serta Indomaret. Hal ini dilakukan tidak hanya untuk meningkatkan margin penjualan dan mempercepat perputaran penjualan barang, namun juga dapat memanipulasi pikiran konsumen untuk melakukan pembelian yang spontan (tanpa terencana). Pada dasarnya berbagai macam program promosi penjualan yang ditawarkan oleh ritel memiliki tujuan yang sama, yaitu untuk lebih meningkatkan lagi kuantitas penjualan produk serta untuk meningkatkan pembelian yang tidak terencana. Oleh karena itu, penting bagi peritel untuk mengetahui apakah konsumen tertarik untuk melakukan pembelian melalui program "purchase with purchase" tersebut berdasarkan motivasi pembelian hedonik atau utilitarian.

\section{TINJAUAN PUSTAKA Promosi Penjualan}

Hermawan (2012) menjelaskan bahwa promosi penjualan merupakan aktivitas pemasaran yang mengusulkan nilai tambah dari suatu produk untuk mendapatkan lebih dari sekedar yang ada dari nilai produk dalam jangka waktu tertentu dalam rangka mendorong pembelian konsumen, efektivitas penjualan, atau mendorong upaya yang akan dilakukan oleh tenaga penjualan. Kotler and Keller (2009) juga mengungkapkan bahwa promosi penjualan merupakan bahan inti dari kampanye pemasaran yang terdiri dari koleksi alat insentif, sebagian besar bersifat jangka pendek yang dirancang untuk menstimulasi pembelian yang lebih cepat atau lebih besar atas produk atau jasa tertentu oleh konsumen atau perdagangan. Penjual menggunakan promosi jenis insentif untuk menarik pencoba baru, menghargai pelanggan setia dan meningkatkan tingkat pembelian kembali pengguna yang jarang membeli.

Lebih lanjut, Tjiptono (2015) juga menjelaskan bahwa pada hakikatnya promosi menawarkan tiga manfaat pokok yang meliputi 1) komunikasi, yaitu memberikan informasi yang bisa menarik perhatian konsumen agar tertarik untuk membeli produk; 2) insentif, berupa kontribusi, konsesi, atau dorongan yang bisa bernilai tambah bagi pelanggan; dan 3) invitasi, yang mengharapkan agar konsumen segera melakukan transaksi pembelian.

\section{Motivasi Belanja}

Menurut Schiffman and Kanuk (2008) motivasi dapat digambarkan sebagai tenaga pendorong dalam diri individu yang memaksa mereka untuk bertindak. Tenaga pendorong tersebut dihasilkan oleh keadaan tertekan yang timbul sebagai akibat kebutuhan yang tidak terpenuhi. Individu secara sadar maupun tanpa sadar berjuang untuk mengurangi ketegangan ini melalui perilaku yang mereka harapkan akan memenuhi kebutuhan mereka dan dengan demikian akan membebaskan mereka dari tekanan yang mereka rasakan. Sedangkan nilai dari belanja (value shopping) melibatkan interaksi antara 
konsumen dengan produk atau jasa yang tidak hanya berkaitan dengan objek itu sendiri, tetapi juga berkaitan dengan pengalaman konsumsi yang dirasakan oleh konsumen (Hoolbrook, 1986). Menurut Nicholls et al. (2002) terdapat dua tipe konsumen yang dapat dikelompokkan berdasarkan tujuan pembelian, yakni konsumen yang didorong oleh nilai utilitarian dan konsumen yang didominasi oleh nilai hedonik.

Bettman dalam Rintamaki et al. (2006) memaparkan perspektif utilitarian berdasarkan pada asumsi bahwa konsumen merupakan pemecah permasalahan yang rasional. Selain itu, Park and Sullivan (2009) mengemukakan bahwa orientasi utilitarian lebih memperhatikan pada aspek efisiensi serta pembelian yang tepat pada waktunya untuk memenuhi tujuan belanja dengan faktor pengganggu yang sangat kecil. Michon et al. (2008) juga mengemukakan bahwa motif utilitarian mencerminkan suatu pemenuhan kebutuhan, sedangkan motif hedonik menjelaskan kepuasan dan ungkapan seseorang yang berhubungan erat dengan pengalaman belanja.

Thaler dalam Kivetz and Zheng (2017) menjelaskan bahwa studi di bidang pemasaran dewasa ini cenderung meneliti bagaimana dampak program promosi terhadap motivasi belanja konsumen daripada mengeksplorasi tentang bagaimana perilaku dan pilihan konsumen. Penelitian yang ada juga memaparkan bagaimana promosi pemasaran dapat mendukung perilaku pembelian konsumen berdasarkan motif utilitarian. Namun, pertanyaan penting yang belum pernah dibahas sebelumnya adalah apa dan bagaimana dampak promosi berdasarkan kategori produk yang berbeda. Oleh karena itu, pada penelitian ini peneliti akan menggunakan simulasi contoh produk untuk kategori "convenience goods" yaitu produk yang biasa dibeli sehari-hari oleh konsumen dan untuk membeli produk tersebut tidak memerlukan keterlibatan tinggi dari konsumen (produk-produk yang beresiko rendah).

\section{Keputusan Pembelian}

Peter and Olson (2013) menjelaskan bahwa strategi promosi tidak hanya memengaruhi kognisi konsumen, tetapi juga perilakunya. Tujuan penjualan, laba, dan pangsa pasar sebuah perusahaan baru dapat dicapai jika konsumen menunjukkan sejumlah perilaku yang meliputi pembelian produknya. Sedangkan Mowen and Minor (2002) mendefinisikan perilaku konsumen (consumer behavior) sebagai suatu studi tentang unit pembelian (buying units) dan proses pertukaran yang melibatkan perolehan, konsumsi, dan pembuangan barang, jasa, pengalaman, serta ide-ide. Definisi ini mengandung sejumlah konsep penting, yakni proses pertukaran (exchange process) di mana segala sumber daya ditransfer di antara kedua belah pihak dan unit pembelian (buying unit) yang berarti bahwa pembelian dapat dilakukan oleh individu atau kelompok.

Selanjutnya Peter and Olson (2013) juga mengemukakan bahwa pengambilan keputusan konsumen (consumer decision making) adalah proses integrasi yang digunakan untuk mengombinasikan pengetahuan untuk mengevaluasi dua atau lebih perilaku alternatif dan memilih satu di antaranya. Hasil proses integrasi tersebut adalah suatu pilihan (choice), secara kognitif menunjukkan intensi perilaku (behavioral intention) yang merupakan suatu rencana (kadang disebut rencana 
keputusan) untuk menjalankan satu perilaku atau lebih.

\section{HIPOTESIS PENELITIAN}

Berdasarkan uraian di atas, maka hipotesis pada penelitian ini dapat dijabarkan sebagai berikut:

$\mathrm{H}_{1}$ : Promosi penjualan dalam bentuk "purchase with purchase" berpengaruh lebih besar terhadap motivasi belanja hedonik.

$\mathrm{H}_{2}$ : Promosi penjualan dalam bentuk "purchase with purchase" berpengaruh lebih kecil terhadap motivasi belanja utilitarian.

$\mathrm{H}_{3}$ : Promosi penjualan dalam bentuk "purchase with purchase" berpengaruh secara positif terhadap keputusan pembelian.

\section{METODE PENELITIAN}

Sampel atau responden yang menjadi partisipan di dalam penelitian ini berjumlah 150 orang mahasiswa. Responden diminta untuk membayangkan bahwa mereka akan membeli produk kebutuhan sehari-hari dalam tiga situasi tertentu. Responden akan dipilih secara acak dan mereka akan menjawab pertanyaan yang ada di dalam kuesioner untuk mengidentifikasi motivasi pembelian mereka. Sedangkan untuk analisis pengolahan data dilakukan dengan menggunakan analisis validitas, reliabilitas, dan regresi.

\section{PEMBAHASAN}

Dari jumlah responden sebanyak 150 orang, yang mempunyai jenis kelamin laki-laki sebanyak 68 orang, dan yang berjenis kelamin perempuan sebanyak 82 orang. Pada penelitian ini pengambilan sampel dilakukan secara acak dan tidak dilakukan uji beda antara jenis kelamin laki-laki dan perempuan. Data profil responden berdasarkan jenis kelamin seperti terlihat pada Tabel 1. Data dari Tabel 1 menunjukkan bahwa populasi mahasiswa laki-laki dan perempuan telah terwakilkan di dalam sampel penelitian, yaitu sebesar 45,3\% dari responden berjenis kelamin laki-laki, dan sebesar 54,7\% dari responden berjenis kelamin perempuan.

Tabel 1

Jenis Kelamin Responden

\begin{tabular}{ccc}
\hline Jenis Kelamin & Persentase & Jumlah \\
\hline Laki-laki & $45.3 \%$ & 68 \\
Perempuan & $54.7 \%$ & 82 \\
\hline TOTAL & $\mathbf{1 0 0 \%}$ & $\mathbf{1 5 0}$
\end{tabular}

Atas data yang diperoleh dilakukan 3 kali uji validitas, yaitu uji validitas studi 1 , uji validitas studi 2 , dan uji validitas studi 3. Hasil uji validitas studi 1 , uji validitas studi 2 , dan uji validitas studi 3 seperti terlihat pada Tabel 2, Tabel 3, dan Tabel 4. Dari hasil uji validitas studi 1 dapat diketahui bahwa semua item pertanyaan yang diberikan memiliki nilai korelasi yang cukup tinggi dengan nilai Sig. < 0,05 sehingga dapat dinyatakan bahwa seluruh item pertanyaan yang dibuat dan diberikan pada kuesioner studi 1 adalah valid dan dapat digunakan untuk mengukur besarnya pengaruh promosi penjualan dalam bentuk "purchase with purchase" terhadap motivasi pembelian hedonik. 
Tabel 2

Hasil Uji Validitas Studi 1

\begin{tabular}{|c|c|c|c|c|c|}
\hline & & $\begin{array}{c}\text { Harga } \\
\text { promo } \\
50 \%\end{array}$ & $\begin{array}{c}\text { Jumlah } \\
\text { item } \\
\text { produk }\end{array}$ & $\begin{array}{c}\text { Motivasi } \\
\text { pembelian } \\
\text { hedonik }\end{array}$ & Keterangan \\
\hline \multirow{2}{*}{$\begin{array}{c}\text { Harga } \\
\text { promo } \\
\mathbf{5 0} \%\end{array}$} & $\begin{array}{c}\text { Pearson } \\
\text { correlation }\end{array}$ & 1 & 0.612 & 0.504 & \multirow[t]{2}{*}{ Valid } \\
\hline & Sig. & - & 0.000 & 0.000 & \\
\hline \multirow{2}{*}{$\begin{array}{c}\text { Jumlah } \\
\text { item } \\
\text { produk }\end{array}$} & $\begin{array}{c}\text { Pearson } \\
\text { correlation }\end{array}$ & 0.612 & 1 & 0.493 & \multirow[t]{2}{*}{ Valid } \\
\hline & Sig. & 0.000 & - & 0.000 & \\
\hline \multirow{2}{*}{$\begin{array}{c}\text { Motivasi } \\
\text { pembelian } \\
\text { hedonik }\end{array}$} & $\begin{array}{c}\text { Pearson } \\
\text { correlation }\end{array}$ & 0.504 & 0.493 & 1 & \multirow[t]{2}{*}{ Valid } \\
\hline & Sig. & 0.000 & 0.000 & - & \\
\hline
\end{tabular}

Dari hasil uji validitas studi 2 seperti terlihat pada Tabel 3 dapat diketahui bahwa semua item pertanyaan memiliki nilai korelasi yang cukup tinggi dengan nilai Sig. < 0,05 sehingga dapat dinyatakan bahwa selu- ruh item pertanyaan pada kuesioner studi 2 adalah valid dan dapat digunakan untuk mengukur besarnya pengaruh promosi penjualan dalam bentuk "purchase with purchase" terhadap motivasi pembelian utilitarian.

Tabel 3

Hasil Uji Validitas Studi 2

\begin{tabular}{|c|c|c|c|c|c|}
\hline & & $\begin{array}{l}\text { Memenuhi } \\
\text { kebutuhan }\end{array}$ & $\begin{array}{c}\text { Hemat } \\
\text { uang } \\
\text { belanja }\end{array}$ & $\begin{array}{l}\text { Motivasi } \\
\text { pembelian } \\
\text { utilitarian }\end{array}$ & Keterangan \\
\hline \multirow{2}{*}{$\begin{array}{l}\text { Memenuhi } \\
\text { kebutuhan }\end{array}$} & $\begin{array}{c}\text { Pearson } \\
\text { correlation }\end{array}$ & 1 & 0.677 & 0.561 & \multirow[t]{2}{*}{ Valid } \\
\hline & Sig. & - & 0.000 & 0.000 & \\
\hline \multirow{2}{*}{$\begin{array}{c}\text { Hemat } \\
\text { uang } \\
\text { belanja }\end{array}$} & $\begin{array}{c}\text { Pearson } \\
\text { correlation }\end{array}$ & 0.677 & 1 & 0.643 & \multirow[t]{2}{*}{ Valid } \\
\hline & Sig. & 0,000 & - & 0.000 & \\
\hline \multirow{2}{*}{$\begin{array}{l}\text { Motivasi } \\
\text { pembelian } \\
\text { utilitarian }\end{array}$} & $\begin{array}{c}\text { Pearson } \\
\text { correlation }\end{array}$ & 0.561 & 0.643 & 1 & \multirow[t]{2}{*}{ Valid } \\
\hline & Sig. & 0.000 & 0.000 & - & \\
\hline
\end{tabular}

Dari hasil uji validitas studi 3 seperti terlihat pada Tabel 4 dapat diketahui bahwa semua item pertanyaan memiliki nilai korelasi yang cukup tinggi dengan nilai Sig. $<0,05$ sehingga dapat dinyatakan bahwa seluruh item pertanyaan pada kuesioner studi 3 adalah valid dan dapat digunakan untuk mengukur pengaruh promosi penjualan dalam bentuk "purchase with purchase" terhadap keputusan pembelian konsumen.

Tabel 4

Hasil Uji Validitas Studi 3

\begin{tabular}{|c|c|c|c|c|}
\hline & & $\begin{array}{c}\text { Tertarik melihat } \\
\text { katalog \& } \\
\text { mempertimbangkan } \\
\text { untuk membeli }\end{array}$ & $\begin{array}{c}\text { Keputusan } \\
\text { pembelian }\end{array}$ & Keterangan \\
\hline \multirow{2}{*}{$\begin{array}{c}\text { Tertarik melihat } \\
\text { katalog \& } \\
\text { mempertimbangkan } \\
\text { untuk membeli }\end{array}$} & $\begin{array}{c}\text { Pearson } \\
\text { correlation }\end{array}$ & 1 & 0.592 & \multirow{2}{*}{ Valid } \\
\hline & Sig. & - & 0.000 & \\
\hline \multirow{2}{*}{$\begin{array}{l}\text { Keputusan } \\
\text { pembelian }\end{array}$} & $\begin{array}{c}\text { Pearson } \\
\text { correlation }\end{array}$ & 0.592 & 1 & \multirow[t]{2}{*}{ Valid } \\
\hline & Sig. & 0.000 & - & \\
\hline
\end{tabular}


Dari data hasil uji reliabilitas yang ditampilkan pada Tabel 5 dapat disimpulkan bahwa masing-masing kuesioner pada ketiga studi yang dilakukan pada penelitian ini memiliki nilai Cronbach's Alpha di atas 0,60 yang artinya bahwa seluruh item per- tanyaan yang terdapat pada kuesioner memiliki tingkat keakuratan atau keandalan yang tinggi serta layak (reliabel) digunakan untuk mengukur pengaruh variabel bebas $(\mathrm{X})$ terhadap variabel terikat (Y).

Tabel 5

Hasil Uji Reliabilitas Kuesioner

\begin{tabular}{ccc}
\hline & Cronbach's Alpha & Keterangan \\
\hline Kuesioner studi 1 & 0.777 & Reliabel \\
\hline Kuesioner studi 2 & 0.834 & Reliabel \\
\hline Kuesioner studi 3 & 0.743 & Reliabel \\
\hline
\end{tabular}

Pada studi yang pertama ini responden diminta untuk membayangkan bahwa mereka akan melakukan kegiatan kemahasiswaan yaitu kunjungan ke perusahaan yang terletak di luar kota, dan mereka akan melakukan persiapan dengan membeli makanan ringan yang akan mereka nikmati selama di perjalanan. Adapun merek makanan ringan yang disimulasikan pada kuesioner adalah Pringles. Pring- les merupakan merek keripik kentang dalam kemasan kaleng yang mudah dijumpai di toko ritel dan merek tersebut sudah banyak diketahui oleh mahasiswa. Untuk simulasi promosi dalam bentuk "purchase with purchase" yang ditawarkan adalah apabila responden membeli keripik kentang Pringles, maka untuk pembelian yang kedua responden akan mendapatkan potongan harga sebesar $50 \%$.

Tabel 6

Hasil Uji Regresi Dan Uji t Studi 1

\begin{tabular}{lcccccccc}
\hline \multirow{2}{*}{ Model } & \multicolumn{2}{c}{$\begin{array}{c}\text { Unstandardized } \\
\text { Coefficients }\end{array}$} & $\begin{array}{c}\text { Standardized } \\
\text { Coefficients }\end{array}$ & & & \multicolumn{2}{c}{ Collinearity Statistics } \\
\cline { 2 - 4 } & B & $\begin{array}{c}\text { Std. } \\
\text { Error }\end{array}$ & Beta & t & Sig. & Tolerance & VIF \\
\hline (Constant) & 1.446 & 0.259 & & 5.577 & 0.000 & & \\
Harga promo $50 \%$ & 0.306 & 0.082 & 0.323 & & 3.723 & 0.000 & 0.625 & 1.600 \\
Jumlah item produk & 0.279 & 0.082 & 0.295 & & 3.394 & 0.001 & 0.625 & 1.600 \\
\hline Dependent Variable: Motivasi pembelian hedonik & & & & & \\
\hline
\end{tabular}

Pada variabel harga promo 50\% seperti terlihat pada Tabel 6 nilai t $>$ $t_{\text {tabel }}(3,723>1,655)$ dan nilai Sig. $0,000<0,05$, maka diputuskan bahwa ketertarikan konsumen untuk mendapatkan harga promo 50\% pada pembelian item yang kedua berpengaruh secara positif dan signifikan terhadap motivasi pembelian hedonik. Sedangkan pada variabel jumlah item produk nilai $t>t_{\text {tabel }}(3,394>1,655)$ dan nilai Sig. 0,001 < 0,05, maka diputuskan bahwa ketertarikan konsumen untuk mendapatkan jumlah item produk yang semakin banyak berpengaruh secara positif dan signifikan terhadap motivasi pembelian hedonik. Untuk nilai tolerance pada kedua variabel menunjukkan angka lebih dari 0,10 (0,625 > $0,10)$ dan nilai VIF kurang dari 10 $(1,600<10)$ sehingga dapat disimpulkan bahwa tidak terjadi multikolinearitas antar variabel bebas yang digunakan. 
Tabel 7

Hasil Uji F Studi 1

\begin{tabular}{lccccc}
\hline \multicolumn{1}{c}{ Model } & $\begin{array}{c}\text { Sum of } \\
\text { Squares }\end{array}$ & df & $\begin{array}{c}\text { Mean } \\
\text { Square }\end{array}$ & F & Sig. \\
\hline Regression & 26.321 & 2 & 13.161 & 32.691 & 0.000 \\
Residual & 59.179 & 147 & 0.403 & & \\
Total & 85.500 & 149 & & & \\
\hline Dependent Variable: Motivasi pembelian hedonik & & \\
Predictors: (Constant), Jumlah item produk, Harga promo 50\% & \\
\hline
\end{tabular}

Berdasarkan hasil uji seperti terlihat pada Tabel 7 dapat diketahui bahwa nilai $F$ pada studi 1 sebesar 32,691 dan $\mathrm{p}<0,05$ sehingga dapat dinyatakan bahwa model regresi yang terdiri dari variabel harga promo 50\% dan variabel jumlah item produk dapat digunakan untuk memprediksi motivasi pembelian hedonic.

Tabel 8

Hasil Uji Regresi Dan Uji t Studi 2

\begin{tabular}{|c|c|c|c|c|c|c|c|}
\hline \multirow{2}{*}{ Model } & \multicolumn{2}{|c|}{$\begin{array}{c}\text { Unstandardized } \\
\text { Coefficients }\end{array}$} & \multirow{2}{*}{$\begin{array}{c}\begin{array}{c}\text { Standardized } \\
\text { Coefficients }\end{array} \\
\text { Beta }\end{array}$} & \multirow[b]{2}{*}{$\mathbf{t}$} & \multirow[b]{2}{*}{ Sig. } & \multicolumn{2}{|c|}{$\begin{array}{c}\text { Collinearity } \\
\text { Statistics } \\
\end{array}$} \\
\hline & B & $\begin{array}{l}\text { Std. } \\
\text { Error }\end{array}$ & & & & Tolerance & VIF \\
\hline (Constant) & 0.874 & 0.245 & & 3.574 & 0.000 & & \\
\hline Memenuhi kebutuhan & 0.237 & 0.086 & 0.231 & 2.765 & 0.006 & 0.542 & 1.846 \\
\hline Hemat uang belanja & 0.511 & 0.088 & 0.486 & 5.807 & 0.000 & 0.542 & 1.846 \\
\hline
\end{tabular}

Pada Tabel 8 nampak variabel memenuhi kebutuhan nilai $t>t_{\text {tabel }}$ $(2,765>1,655)$ dan nilai Sig. 0,006 < 0,05, maka diputuskan bahwa ketertarikan konsumen untuk dapat memenuhi kebutuhan perawatan rambut berpengaruh secara positif dan signifikan terhadap motivasi pembelian utilitarian. Sedangkan pada variabel hemat uang belanja nilai $\mathrm{t}>\mathrm{t}_{\text {tabel }}(5,807>$ 1,655) dan nilai Sig. $0,000<0,05$ maka diputuskan bahwa ketertarikan konsumen untuk dapat berhemat uang belanja berpengaruh secara positif dan signifikan terhadap motivasi pembelian utilitarian. Untuk nilai tolerance kedua variabel menunjukkan angka lebih dari 0,10 $(0,542>0,10)$ dan nilai VIF kurang dari $10(1,846<10)$ sehingga dapat disimpulkan bahwa tidak terjadi multikolinearitas antar variabel bebas.

Tabel 9

Hasil Uji F Studi 2

\begin{tabular}{lccccc}
\hline \multicolumn{1}{c}{ Model } & $\begin{array}{c}\text { Sum of } \\
\text { Squares }\end{array}$ & df & $\begin{array}{c}\text { Mean } \\
\text { Square }\end{array}$ & F & Sig. \\
\hline Regression & 37.616 & 2 & 18.808 & 58.258 & 0.000 \\
Residual & 47.457 & 147 & 0.323 & & \\
Total & 85.073 & 149 & & & \\
\hline Dependent Variable: Motivasi pembelian utilitarian & & \\
Predictors: (Constant), Hemat uang belanja, Memenuhi kebutuhan & \\
\hline
\end{tabular}


Berdasarkan hasil uji Tabel 9 dapat diketahui bahwa nilai $\mathrm{F}$ pada studi 2 sebesar 58,258 dan $\mathrm{p}<0,05$ sehingga dapat dinyatakan bahwa model regresi yang terdiri dari variabel memenuhi kebutuhan dan variabel hemat uang belanja dapat digunakan untuk memprediksi motivasi pembelian utilitarian.

Tabel 10

Pengujian Hipotesis 1 dan 2

\begin{tabular}{llcc}
\hline \multicolumn{1}{c}{ Hipotesis Yang Diusulkan } & Nilai F & Keputusan \\
\hline $\mathrm{H}_{1}: \begin{array}{l}\text { Promosi penjualan dalam bentuk "purchase } \\
\text { with purchase" berpengaruh lebih besar } \\
\text { terhadap motivasi belanja hedonik. }\end{array}$ & 32.691 & Ditolak \\
\hline $\mathrm{H}_{2}: \begin{array}{l}\text { Promosi penjualan dalam bentuk "purchase } \\
\text { with purchase" berpengaruh lebih kecil } \\
\text { terhadap motivasi belanja utilitarian. }\end{array}$ & 58.258 & Ditolak \\
\hline
\end{tabular}

Dari data yang ditampilkan pada Tabel 10 dapat ditarik simpulan bahwa berdasarkan nilai $\mathrm{F}$ secara simultan pengaruh promosi dalam bentuk "purchase with purchase" berpengaruh lebih kecil terhadap motivasi pembelian hedonik dan menunjukkan pengaruh yang lebih besar terhadap motivasi pembelian utilitarian, sehingga untuk hasil pengujian $\mathrm{H}_{1}$ dan $\mathrm{H}_{2}$ keduanya ditolak. Hal ini berarti bahwa responden lebih termotivasi untuk memanfaatkan harga promo dalam bentuk "purchase with purchase” sesuai dengan apa yang menjadi kebutuhannya saat itu serta untuk menghemat uang belanja dan bukan termotivasi untuk mendapatkan po- tongan diskon 50\% untuk pembelian produk yang kedua atau untuk mendapatkan produk dengan jumlah yang lebih banyak.

Selanjutnya, untuk studi yang ketiga peneliti ingin menganalisis pengaruh promosi dalam bentuk "purchase with purchase" versi lain terhadap keputusan pembelian konsumen. Pada studi yang ketiga ini responden diminta untuk membayangkan bahwa mereka sedang berada di toko ritel dan terdapat katalog untuk beberapa pilihan merek produk yang menampilkan format promosi yaitu dengan menambahkan Rp. 1.000,- responden bisa mendapatkan dua produk yang sama sekaligus.

Tabel 11

Hasil Uji Regresi dan Uji t Studi 3

\begin{tabular}{|c|c|c|c|c|c|}
\hline \multirow[t]{2}{*}{ Model } & \multicolumn{2}{|c|}{$\begin{array}{l}\text { Unstandardized } \\
\text { Coefficients }\end{array}$} & \multirow{2}{*}{$\begin{array}{c}\text { Standardized } \\
\text { Coefficients }\end{array}$} & \multirow[b]{2}{*}{$t$} & \multirow[b]{2}{*}{ Sig. } \\
\hline & B & Std. Error & & & \\
\hline (Constant) & 1.598 & 0.222 & & 7.206 & 0.000 \\
\hline $\begin{array}{l}\text { Tertarik melihat katalog \& } \\
\text { mempertimbangkan untuk } \\
\text { membeli }\end{array}$ & 0.570 & 0.064 & 0.592 & 8.930 & 0.000 \\
\hline Dependent Variable: Keput & mbelian & & & & \\
\hline
\end{tabular}


Dari data pada Tabel 11 nampak bahwa nilai $\mathrm{t}>\mathrm{t}_{\text {tabel }}(8,930>1,655)$ dan nilai Sig. $0,000<0,05$, maka diputuskan bahwa ketertarikan konsumen untuk melihat katalog dan mempertimbangkan membeli produk dengan promosi penawaran semacam itu berpengaruh secara positif dan signifikan terhadap keputusan pembelian konsumen. Sedangkan untuk pengujian hipotesis yang ketiga dapat dilihat dari data Tabel 11 di mana nilai $\mathrm{t}$ menunjukkan angka positif sebesar 8,930 dengan nilai Sig. 0,000 < 0,05, sehingga dapat diputuskan bahwa hipotesis ketiga $\left(\mathrm{H}_{3}\right)$ diterima atau promosi penjualan dalam bentuk "purchase with purchase” berpengaruh secara positif terhadap keputusan pembelian.

Hal ini berarti bahwa format promosi yang menonjolkan keterangan seperti konsumen hanya perlu menambah Rp. 1.000,- maka mereka bisa mendapatkan dua produk terbukti berdampak positif terhadap keputusan pembelian. Namun hal ini masih diperlukan pengujian lebih lanjut karena belum dapat terdeteksi apa yang menjadi motivasi pembelian konsumen, karena ritel juga harus menentukan item produk dan merek produk apa yang menjadi favorit atau jenis produk apa yang benar-benar dibutuhkan oleh konsumen. Hal tersebut perlu untuk dipertimbangkan meskipun konsep promosi dengan hanya menambahkan Rp. 1.000,- saja konsumen bisa mendapatkan dua item produk sekaligus telah mampu menarik minat pembelian konsumen namun jika merek dan item produk yang tertera di dalam katalog produk ternyata bukanlah merek atau item produk yang menjadi favorit dan tidak dibutuhkan oleh konsumen pada saat itu, maka bisa jadi konsumen akan mengurungkan niat atau membatalkan keputusan pembeliannya.

\section{SIMPULAN}

Berdasarkan hasil pembahasan pada bagian sebelumnya, maka dapat ditarik beberapa simpulan sebagai berikut:

1. Promosi "purchase with purchase" dengan format potongan harga sebesar 50\% untuk pembelian item yang kedua berpengaruh positif dan signifikan terhadap motivasi pembelian hedonik.

2. Promosi "purchase with purcha$s e$ ” dengan format konsumen bisa menebus produk dengan harga khusus yang disertai dengan nominal pembelanjaan tertentu berpengaruh positif dan signifikan terhadap motivasi pembelian utilitarian.

3. Promosi "purchase with purcha$s e$ " dengan format hanya menambah Rp. 1.000,- maka konsumen bisa mendapatkan dua item produk sekaligus juga berpengaruh positif dan signifikan terhadap keputusan pembelian konsumen.

4. Promosi dalam bentuk "purchase with purchase" lebih besar berpengaruh terhadap motivasi pembelian utilitarian.

\section{SARAN}

Adapun saran yang dapat dikemukakan dari hasil penelitian yang telah dilakukan, antara lain:

1. Harga promosi dalam bentuk "purchase with purchase" dapat diimplementasikan pada ritel karena berdampak positif untuk meningkatkan motivasi pembelian hedonik dan utilitarian.

2. Dalam mengimplementasikan harga promosi dalam bentuk "pur- 
chase with purchase" ritel harus memperhatikan merek produk yang menjadi favorit atau yang paling dibutuhkan oleh konsumen agar penjualan semakin meningkat.

3. Strategi promosi dalam bentuk "purchase with purchase" juga dapat diimplementasikan pada saat-saat tertentu seperti ramadhan, menjelang Idul Fitri, Natal, atau pada saat memasuki tahun ajaran baru sekolah di mana biasanya pembelian konsumen semakin meningkat pada moment tersebut.

4. Penyampaian informasi tentang adanya promosi dalam bentuk "purchase with purchase" seharusnya tidak hanya menggunakan brosur atau katalog saja, namun juga memanfaatkan beberapa media yang bisa menjangkau khalayak luas seperti internet dan media sosial seperti line, whatsapp, instagram, agar informasinya semakin banyak diketahui oleh konsumen.

\section{DAFTAR KEPUSTAKAAN}

Feinberg, F. M., A. Krishna, and J. Z. Zhang, 2002, Do We Care What Others Get? A Behaviorist Approach to Targeted Promotions, Journal of Marketing Research, Vol. 39, No. 3, page 277-291.

Hermawan, A., 2012, Komunikasi Pemasaran, Penerbit Erlangga, Jakarta.

Holbrook, M. B., 1986, The Role of Affect in Consumer Behaviour: Emerging Theories and Applications, Lexington, Heath, MA.
Kamins, M. A., V.S. Folkes, and A. Fedorikhin, 2009, Promotional Bundles and Consumers' Price Judgment: When The Best Things in Life are not Free, Journal of Consumer Research, Vol. 36, page 660-670.

Kivetz, R. and Y. Zheng, 2017, The Effects of Promotions on Hedonic Versus Utilitarian Purchases, Journal of Consumer Psychology, Vol. 27, No. 1, page 59-68.

Kotler, P. and K. L. Keller, 2009, Manajemen Pemasaran, Edisi Ketiga Belas, Penerbit Erlangga, Jakarta.

Liu, H-H, and H-Y Chou, 2015, The Effects of Promotional Frames of Sales Packages on Perceived Price Increases and Repurchase Intentions, International Journal of Marketing, Vol. 32, page 23-33.

Michon, R., H. Yu, D. Smith, and J-C Chebat, 2008, The Influence of Mall Environment on Female Fashion Shoppers' Value and Behaviour, Journal of Fashion Marketing and Management, Vol. 12, No. 4, page 456-468.

Monroe, K. B., 2003, Pricing: Making Profitable Decisions, 3rd Edition, Burr Ridge, IL: McGraw-Hill/Irwin.

Mowen, J. C., and M. Minor, 2002, Perilaku Konsumen, Edisi Kelima, Penerbit Erlangga, Jakarta.

Nicholls, J. A. F., F. Li, C. J. Kranendonk, and S. Roslow, 2002, The Seven Year Itch? Mall Shoppers Across Time, Journal of Con- 
sumer Marketing, Vol. 19, No. 2, page 149-165.

Park, E. J. and F. Sullivan, 2009, Market Segmentation With Respect to University Student's Clothing Benefits Sought, International Journal of Retail \& Distribution Management, Vol. 37, No. 2, page 182201.

Peter, J. P. and J. C. Olson, 2013, Perilaku Konsumen \& Strategi Pemasaran, Edisi Kesembilan, Penerbit Salemba Empat, Jakarta.

Raghubir, P., 2004, Free Gift With Purchase: Promoting or Discounting The Brand, Journal of Consumer Physicology, Vol. 14, page 181-186.

Rintamaki, T., A. Kanto, H. Kuusela, and M. T. Spence, 2006, Decomposing the Value of Department Store Shopping Into Utilitarian, Hedonic and Social Dimensions, International Journal of Retail \& Distribution Management, Vol. 34, No. 1, page 6-24.

Schiffman, L. G. and L. L. Kanuk, 2008, Consumer Behavior, Edisi Ketujuh, Penerbit PT Indeks, Jakarta.
Smith, M. F. and I. Sinha, 2000, The Impact of Price and Extra Product Promotions on Store Preference, International Journal of Retail \& Distribution Management, Vol. 28, page 83-92.

Tjiptono, F., 2015, Strategi Pemasaran, Edisi Keempat, Penerbit Andi, Yogyakarta.

Xia, L., M. Kukar-Kinney, and K. B. Monroe, 2010, Effects of Consumers' Efforts on Price and Promotions Fairness Perceptions, Journal of Retailing, Vol. 86, No. 1, page 1-10.

Xia, L., K. B. Monroe, and J. L. Cox, 2004, The Price is Unfair! A Conceptual Framework of Price Fairness Perceptions, Journal of Marketing, Vol. 68, page 1-15. 